\title{
A OCORRÊNCIA DE FLACOPIMPLA GAULD NO BRASIL (HYMENOPTERA, ICHNEUMONIDAE, PIMPLINAE) ${ }^{1}$
}

\author{
Vinalto Graf ${ }^{2}$ \\ Alice Fumi Kumagai ${ }^{3}$
}

\begin{abstract}
The ocCurRence of FlaCopimpla Gauld in Brazil (Hymenoptera, ICHNEUMONIDAE, PIMPLINAE). Flacopimpla was described with one species, $F$. varelae by Gauld (1991) from Costa Rica (only females, Guanacaste National Park). This genus is recorded for the first time in Brazil and a new species, $F$. sulina, is described and the distribution in southeast and south of Brazil is mapped (Minas Gerais: Belo Horizonte; Paraná: Telêmaco Borba, Ponta Grossa, Curitiba, Colombo, Antonina). KEY WORDS. Hymenoptera, Ichneumonidae, Pimplinae, Flacopimpla, distribution taxonomy
\end{abstract}

O gênero Flacopimpla e a espécie $F$. varelae foram descritos por GAULD (1991) para três fêmeas da ichneumofauna da Costa Rica, coletadas no Parque Nacional Guanacaste. Esta espécie, conforme Gauld, se assemelha às espécies dos gêneros Zatypota Foerster, 1868, Eruga Townes, 1960 e Acrodactyla Haliday, 1837, por apresentar em comum uma área rômbica no segundo tergito, a parte apical da mediela da asa posterior fortemente arqueada e ovipositor curto. Difere desses gêneros por apresentar nas tíbias posteriores, um sulco longitudinal na superfície interna, sem pêlos e as mandíbulas com o dente superior muito longo e curvado para cima. A espécie do Brasil, que se descreve a seguir, apresenta outras características dos Polysphinctini e de Flacopimpla como: cabeça preta com clípeo amarelo; margem clipeal fracamente côncava; palpos maxilares com cinco e labiais com quatro artículos; sulco subocular ausente; pronoto sem crista longitudinal médiodorsal e com fraco sulco transversal; epômia pouco desenvolvida; quarto artículo tarsal subquadrado e terceiro tergito do metasoma com uma área central rômbica.

A descrição da nova espécie seguiu a de $F$. varelae, mas com a terminologia de TowNES (1969). As medidas entre parênteses são em milímetros. O material tipo foi depositado na coleção de Entomologia Pe. J.S. Moure, do Departamento de Zoologia da Universidade Federal do Paraná (DZUP - Curitiba), bem como os parátipos, exceto os de Belo Horizonte e Curitiba, no Departamento de Zoologia da Universidade Federal de Minas Gerais (UFMG - Belo Horizonte).

1) Contribuição número 995 do Departamento de Zoologia, Universidade Federal do Paraná.

2) Departamento de Zoologia, Universidade Federal do Paraná. Caixa Postal 19020, 81531-990 Curitiba, Paraná, Brasil. Bolsista do CNPq.

3) Departamento de Zoologia, Universidade Federal de Minas Gerais. Caixa Postal 486, 31270-970 Belo Horizonte, Minas Gerais, Brasil. 
Flacopimpla sulina foi coletada com armadilhas de Malaise (modelo Townes, 1972) instaladas em áreas de mata. A Estação Ecológica da Universidade Federal de Minas Gerais (Belo Horizonte) é coberta por uma mata secundária, perenifólia (formação primária em regeneração) e nas demais localidades, "floresta úmida subtropical". As altitudes dos locais de coleta variam de 915 a $750 \mathrm{~m}$ (Colombo, 915m; Curitiba, 900m; Ponta Grossa, 880m; Belo Horizonte, 858m; Telêmaco Borba, $750 \mathrm{~m}$ ), exceto em Antonina, com aproximadamente $60 \mathrm{~m}$.

\section{Flacopimpla sulina sp.n.}

Figs 1-6

Fêmea. Coloração: cabeça preta, com o clípeo, menos na sua base, aparelho bucal, escapo e pedicelo no seu lado ventral, esbranquiçados. Tórax quase todo ferrugíneo-avermelhado, com as margens anterior do pronoto e ântero-lateral do mesoscuto, propleura, mesepimero, metapleura, tégulas e base das asas, esbranquiçadas. Pernas I, II e III esbranquiçadas, as anteriores com fêmur, tíbia e tarsos ferrugíneo-pálidos; distitarsos um pouco enegrecidos; trocanter e fềmur com pequena mancha preta na base; pernas posteriores esbranquiçadas, mas enegrecidas no lado externo da coxa, na base do trocanter e do fêmur, ao longo da face externa do fêmur; nas partes basal e distal da tíbia e nos tarsos, menos a parte proximal do basitarso e os esporões tibiais, esbranquiçados. Asas hialinas, venação e pterostigma pretos. Propódeo enegrecido na margem posterior. Abdômen preto, com a margem anterior dos tergitos II-V e estreita faixa na margem posterior dos tergitos V-VII, esbranquiçadas. Valvas pretas, ovipositor ferrugíneo.

Clípeo proeminente, convexo, liso, brilhante, apicalmente pouco côncavo no meio, a largura o dobro do comprimento $(0,36: 0,18)$, protuberante, com pontuação setífera esparsa, pêlos clipeais $(0,14)$ mais longos que os da face. Área malar mais longa que a largura basal da mandíbula $(0,14: 0,12)$, com uma faixa coriácea que se estende do olho à base da mandíbula. Face subquadrada $(0,44: 0,40)$, polida, um pouco protuberante no meio e finamente alutácea; distância interorbital superior quase igual a inferior $(0,48: 0,46)$; diâmetro do ocelo lateral um pouco maior que sua distância ao olho $(0,12: 0,10)$. Gena, em vista lateral, mais estreita que o olho $(0,26: 0,36)$. Carena occipital completa unida à carena oral bem acima da base da mandíbula. Mandíbulas fortemente afiladas para o ápice, dente superior mais longo que o inferior e voltado para cima. Palpos maxilares longos, alcançando a margem posterior da coxa anterior. Mesoscuto liso, finamente mate, quase glabro, com poucos pêlos esparsos na parte central anterior do lobo mediano. Mesopleura lisa e brilhante, glabra no meio, com pêlos esparsos em cima e embaixo, mais densos no mesosterno. Metapleura lisa e brilhante, com pontuação setífera muito fina e esparsa. Propódeo fosco, com carenas curtas, uma no meio e duas laterais junto à margem posterior e às carenas pleurais, que se estendem desde a margem posterior até os espiráculos. Asa anterior com nérvulo oposto à veia basal e a subdiscoidal interceptando o pós-nervelo no meio; primeira intercubital pouco distinta. Tergito I com comprimento 1,29 vezes a largura posterior e 3,33 vezes o pecíolo $(0,80: 0,62: 0,24 \mathrm{~mm})$, fosco, com profundo sulco em V; carena longitudinal látero- 


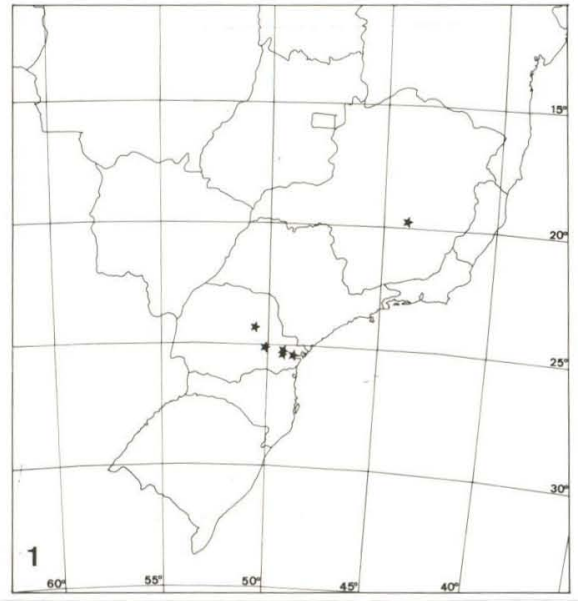

Fig. 1. Distribuição geográfica de Flacopimpla sulina na região Sudeste e Sul do Brasil.

mediana curta ( 0,25 do segmento) e a carena lateral completa. Os tergitos II-V foscos nas partes anterior e central, as áreas posteriores ao sulco em $\mathrm{V}$, lisas e brilhantes com fosco muito fraco nos lados. Ovipositor 0,62 vezes o comprimento da tíbia posterior, pouco curvo para cima, com o ápice muito afilado e sem dentes apicais.

Comprimento total $5,75 \mathrm{~mm}$; comprimento da asa anterior $5,50 \mathrm{~mm}$; comprimento da antena $6,08 \mathrm{~mm}$; comprimento da tíbia posterior $1,94 \mathrm{~mm}$; comprimento do ovipositor $1,20 \mathrm{~mm}$;

Macho. Como a fêmea, mas sem o sulco longitudinal na superfície interna da tíbia posterior.

Comprimento total $5,17 \mathrm{~mm}$; comprimento da asa anterior $4,0 \mathrm{~mm}$; comprimento da antena $5,83 \mathrm{~mm}$; comprimento da tíbia posterior $1,66 \mathrm{~mm}$.

Holótipo fêmea. BRASIL, Paraná, Curitiba (Capão da Imbuia), 11.VIII.1995, A. F. Kumagai leg., e alótipo de Colombo, 18.V.1987, Projeto Profaupar leg. (Levantamento da Fauna Entomológica do Estado do Paraná, 1986/87) (DZUP).

Parátipos. Brasil, Minas Gerais: Belo Horizonte (Estação Ecológica da UFMG), uma fêmea 6-12.VIII.1991; uma fêmea 8-14.X.1991; duas fêmeas 29.X4.XI.1991; duas fêmeas 5-11.XI.1991; cinco fêmeas 12-18.XI.1991; uma fêmea 26.XI.1991; duas fêmeas 3-9.XII.1991; duas fêmeas 17-23.XII.1991; uma fêmea 31.XII-6.I.1992; A.F. Kumagai leg.; Paraná, Telêmaco Borba, uma fêmea 6.IV.1987; Projeto Profaupar leg.; Ponta Grossa, uma fêmea 25.VIII.1986; uma fêmea 15.IX.1986; uma fêmea 1.XII.1986; uma fêmea 15.XII.1986; uma fêmea 29.XII.1986; uma fêmea 12.I.1987; uma fêmea 29.VI.1987; Projeto Profaupar leg.; Curitiba, uma fêmea 30.VI.1995; uma fêmea 7.VII.1995; uma fềmea 21.VII.1995; uma fềmea 28.VII.1995; uma fêmea 10.XI.1995; uma fêmea 17.XI.1995; duas fêmeas 15.XII.1995; uma fêmea 22.XII.1995; uma fêmea 5.I.1996; uma fêmea 26.I.1996; uma fêmea 2.II.1996; uma fêmea 23.II.1996; uma fêmea 19.IV.1996; uma fêmea 17.V.1996; A. F. Kumagai leg.; Colombo, uma fêmea 2.II.1987; Projeto Profaupar leg.; Antonina, uma fêmea 15.IX.1986; uma fêmea 13.X.1986; Projeto Profaupar leg. . 

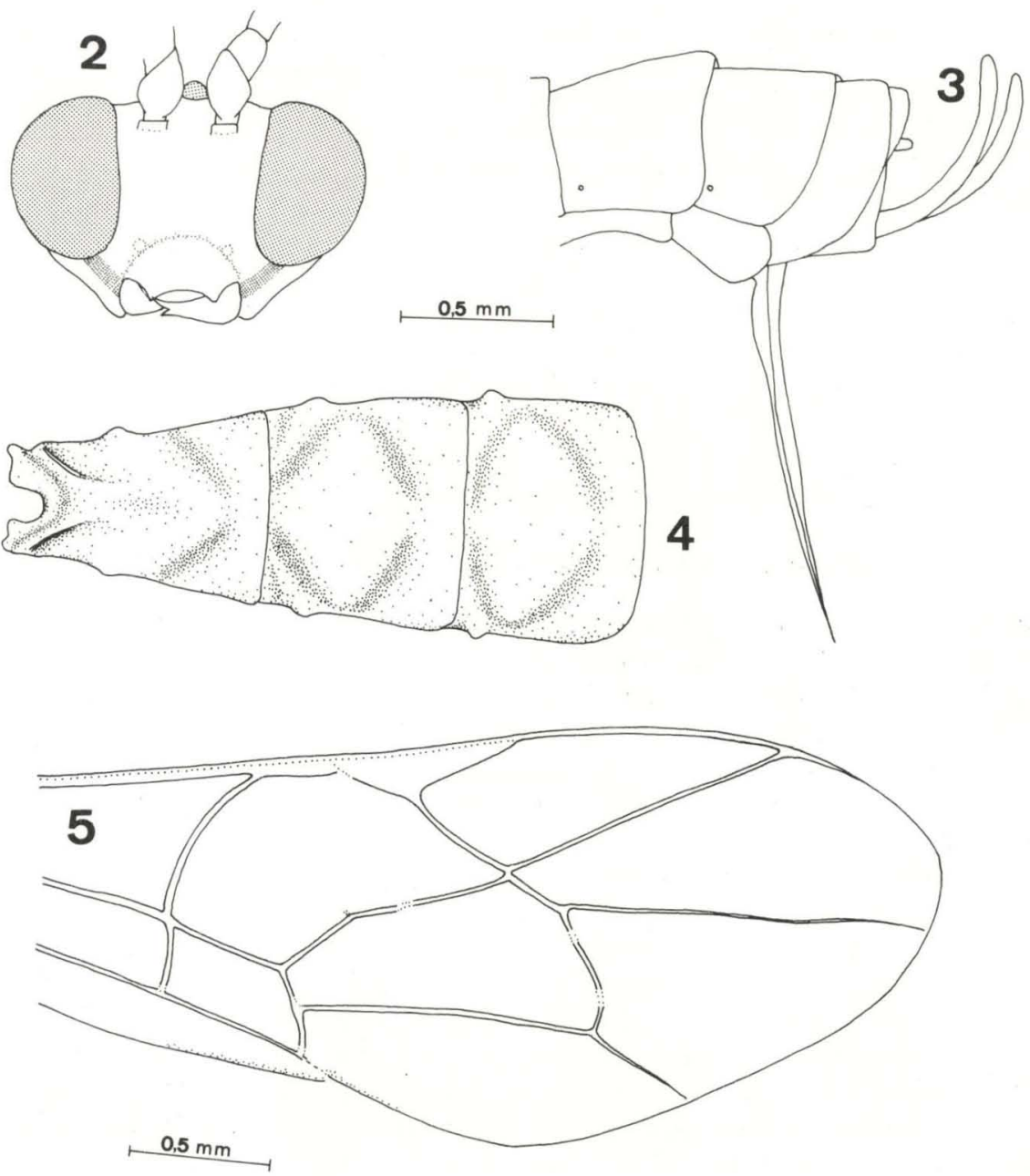

\section{6}

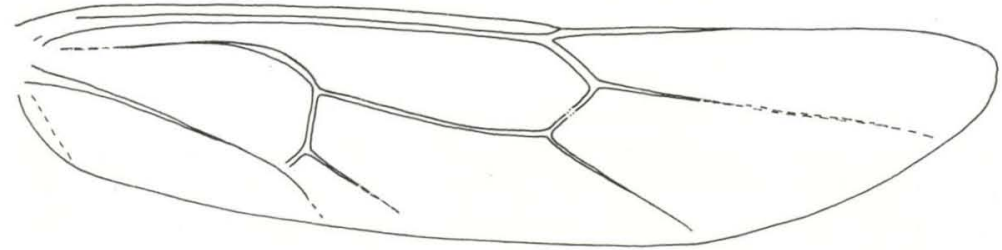

Figs 2-6. Flacopimpla sulina, fêmea. (2) Cabeça em vista anterior; (3) vista lateral da parte posterior do abdômen; (4) vista dorsal dos tergos I a III; (5) parte distal da asa anterior; (6) asa posterior. 
Variação. Clípeo preto como a face, mas com a metade ou margem distal esbranquiçada. Primeiro flagelômero preto. Mesoscuto látero-anteriormente esbranquiçado, o escutelo branco, exceto na base. Metapleuras ferrugíneo-avermelhadas a pretas. Propódeo preto, ferrugíneo-enegrecido ou ferrugíneo enegrecido com os lados pretos. Faixa esbranquiçada na base dos tergos II-V, mais larga nos exemplares de Belo Horizonte.

Discussão. Flacopimpla sulina é parecida a $F$. varelae, mas difere na coloração (sem manchas pretas laterais nos fêmures anteriores e médios), nas proporções (clípeo mais largo que alto; face subquadrada, em $F$. varelae é transversal; espaço malar pouco mais longo que a largura da base da mandíbula; dentes mandibulares superiores mais curtos; palpos maxilares mais longos, alcançando a margem posterior da coxa anterior) e nas estruturas (larga faixa coriácea entre o olho e a base da mandíbula, estreita em $F$. varelae; as carenas pleurais do propódeo alcançam os espiráculos, em $F$. varelae são mais curtas, da margem posterior até a metade do propódeo; propódeo com três carenas longitudinais posteriores curtas; em $F$. varelae propódeo sem carenas e com fraco canal mediano; primeiro tergito com comprimento 1,3 vezes a largura posterior, $1,5 \mathrm{em} F$. varelae; asa anterior com nérvulo oposto à veia basal, um pouco distal à veia basal em $F$. varelae). Brasil.

Etimologia. sulina, referência à distribuição da espécie no sudeste e sul do

\section{REFERÊNCIAS BIBLIOGRÁFICAS}

Gauld, I.D. 1991. The Ichneumonidae of Costa Rica, 1. Mem. Amer. Entomol. Inst. 47: 1-589.

Townes, H. 1969. The Genera of Ichneumonidae. Part 1. Mem. Amer. Entomol.

Inst. 12: 1-300. 1972. A Light-weight Malaise Trap. Ent. News, 83: 239-247.

Recebido em 13.III.1997; aceito em 10.IX.1997. 